\title{
Implementation and performance of a matrix organization structure
}

\author{
John A. Kuprenas* \\ Department of Civil Engineering, University of Southern California, Los Angeles, CA 90089-2531, USA
}

Received 23 August 2000; received in revised form 9 January 2001; accepted 14 September 2001

\begin{abstract}
This paper presents a case study in the implementation and use of a matrix organization. This paper describes the matrix organization installed at the City of Los Angeles, Bureau of Engineering. The work explains how the need for a matrix structure was identified, reviews the creation of the matrix, describes the problems associated with the implementation of the new structure, and evaluates the effectiveness of the project management process within the matrix organization. The study finds that although implementation problems have occurred, the performance of the organization while operating under a matrix structure has improved with respect to project delivery. (C) 2002 Elsevier Science Ltd and IPMA. All rights reserved.
\end{abstract}

Keywords: Managing program; Managing projects; Management structure

\section{Introduction}

Matrix management began in the 1960's as an organizational means to meet the needs of the aerospace industries [1]. The government contract selection process required a project-oriented system directly linked to top-management. In order to meet this requirement, the aerospace firms established a set of horizontal project groups over their traditional vertical functional organizations [2]. In creating such an organization, many employees would end up working both under a department head and a project manager of an interdisciplinary project team. When depicted on paper, this crossing of organizational lines is easily be represented by a grid of a matrix; hence, the term Matrix Organization was created [2].

When compared with other organizational forms, a matrix organization is a mixed form in which traditional hierarchy is overlaid by some form of lateral authority, influence, or communication. This overlay present in a matrix creates two chains of command - one along the functional lines, the other along project lines [3]. Given the complexity of project management in the actual business world, the matrix structure is often used where the need for strong technical assistance across many areas is required [4]. It is still particularly popular in the

\footnotetext{
* Tel.: + 1-213-740-0603; fax: + 1-213-744-1426

E-mail address: kuprenas@mizar.usc.edu
}

large-scale consulting, aerospace, and construction industries [5].

This paper presents a case study in the implementation and use of a matrix organization. This paper describes the matrix organization installed at the City of Los Angeles, Bureau of Engineering. The work explains how the need for a matrix structure was identified, reviews the creation of the matrix, describes the problems associated with the implementation of the new structure, and evaluates the effectiveness of the project management process within the matrix organization. This paper benefits practicing project managers by presenting a case study in which many matrix organization implementation and operation difficulties identified through past research were in fact manifested in the organizational shift. Managers can learn how this case study organization solved these problems and the effectiveness of the solutions, as well as the effectiveness of the entire organizational structure change. Managers and academics will also benefit through a discussion of additional project management research needs in the areas of matrix structures and organizational performance.

\section{Development of the matrix}

The case study takes place in the city of Los Angeles. With a population of over 3.5 million persons, Los Angeles is located along the southern coast of the State 
of California in the western United States. The City is 468 square miles and has an irregular shape with the most expansive areas being in the northern part of the city and tapering down to a strip in the southern portion. Los Angeles experiences a Mediterranean type of climate (dry summers and wet winters) with an average temperature of $18{ }^{\circ} \mathrm{C}$. The City of Los Angeles, Department of Public Works is the City's third largest Department with over 5500 employees and is responsible for construction, renovation, and the operation of City facilities and infrastructure. The Bureau of Engineering, with over 900 employees (with over 550 engineers), is a part of the City of Los Angeles' Department of Public Works and is responsible for the planning, design, and construction management of capital improvement projects for the city including municipal facilities, stormwater, sewer, street and other infrastructures projects.

Although the quality of the Bureau of Engineering's designs has always been excellent, some past programs within the Bureau experienced significant delays and cost overruns in the design and construction of projects. In 1993 a new Mayor was elected for Los Angeles, and these past overruns were no longer tolerated. The Mayor felt that many groups within the City's Municipal Government had become entrenched in bureaucracy, and in order to save the city money, some organizations (including the Bureau of Engineering) could be privatized or reorganized to be run more efficiently at a lower cost. Hence, in the time period from 1994 to 1996 several groups were commissioned by the Mayor to analyze the Department of Public Works and the Bureau of Engineering. The groups studied the Bureau's past performance with respect to capital project design and compared the costs to similar engineering organizations within the United States. The groups also studied the Bureau's organizational structure and interviewed dozens of Bureau staff to better understand the reporting and communication relationships

All study findings were similar. The first study identified the need for a comprehensive project control system, a coordinated plan of Bureau programs, and a new management structure to create this plan [6]. The second report identified the need to organize the Bureau around its key programs, to create a project management organization to improve accountability for each project, and to correct or improve the senior engineers' high degree of autonomy that had made it difficult to effectively manage projects and programs that cross divisional boundaries [7]. The third report identified the need to establish a group of project managers (separate from project engineers) to manage the design and construction phases of capital projects and the need for a multi-year capital improvement program (CIP) with priorities to be used to identify type and amount of required resources [8].
Consistent to all of these reviews was the specific recommendation to move from the existing functional organization toward a project management style of project delivery and organization. The reports asserted that within the current system, little or no ownership of projects existed and no performance measures were in place to measure project status. As a result, in February 1997, the Bureau of Engineering executive staff and the Board of Public Works mandated a dramatic shift to improve project delivery. Despite well documented difficulties in the use of a matrix structure [9-11] all of the Bureau divisions were to be organized into a matrix organization with a project manager being the focus for project delivery with project conception-to-conclusion responsibility. Several organizational options were considered before the final matrix structure was selected, but in the final analysis, a matrix organization was selected.

A matrix was selected because past research has shown that of the existing conditions and requirements within the Bureau are the classic elements that would make the structure a strong choice. The Bureau conditions of

- outside pressure for dual focus (between project delivery and state of the art design);

- pressures for high information processing (multiple diverse projects and reporting requirements); and

- pressures for shared resources (for all non Civil design disciplines);

were all identified by Tatum as key basic conditions for selection of a matrix [12]. Other reasons also identified to favor the use of the matrix were the necessary inherent control of client group projects/programs (the Bureau's principle function) in the structure while maintaining functional authority levels (needed for a public organization such as the Bureau). Other options considered but not used are shown in Fig. 1.

Even after selecting a matrix structure, the Bureau still needed to determine which type of matrix to use since the matrix structure can operate in may different ways. Larson and Gobeli [1] defined three-matrix types - functional, balanced, and project. The amount of authority of the functional manager differentiates between the three types. A summary of the types of matrix is shown below:

Functional Matrix: in a functional matrix, staff involved in the delivery process remain under control of the functional manager, while project managers are formally designated to oversee the project across different functional areas. As a result, project managers have limited authority over functional staff and, therefore, primarily plan and coordinate the project. Under this form of matrix, functional managers retain primary responsibility for their specific segments of the project [1]. 


\section{FUNCTIONAL STRUCTURE}

A functional structure is the organizational structure under which the Bureau had traditionally operated. This structure placed emphasis on the technical expertise of the functional divisions of the bureau. When one function completed their portion of the project, the project was passed on to the next technical group to provide the next function. Under this approach there was little emphasis on schedule and overall budget as projects were reworked many times before passed on to the next function, and as such technical groups could never be sure when a project will reach their shop. Hence, resources were poorly allocated and bottlenecks formed.

\section{INDEPENDENT PROGRAM}

An independent program concept with all resources needed to complete a program or project included within the program was also considered. This option required an increase in Bureau staff because technical designers and specialist personnel must be housed within each self-contained program. Staff is not shared from program to program. Under this approach, the program projects are certain to be completed but at a premium staff cost because of duplicate staff requirements.

\section{GEOGRAPHIC BASED}

A geographical-based concept with all resources divided into regions within the City was also considered. This structure required technical staff to be based throughout the City. This approach would have been the most responsive to immediate political needs, but emphasis on the long-term capital improvement programs was missing and sharing of knowledge and expertise within the Bureau was absent.
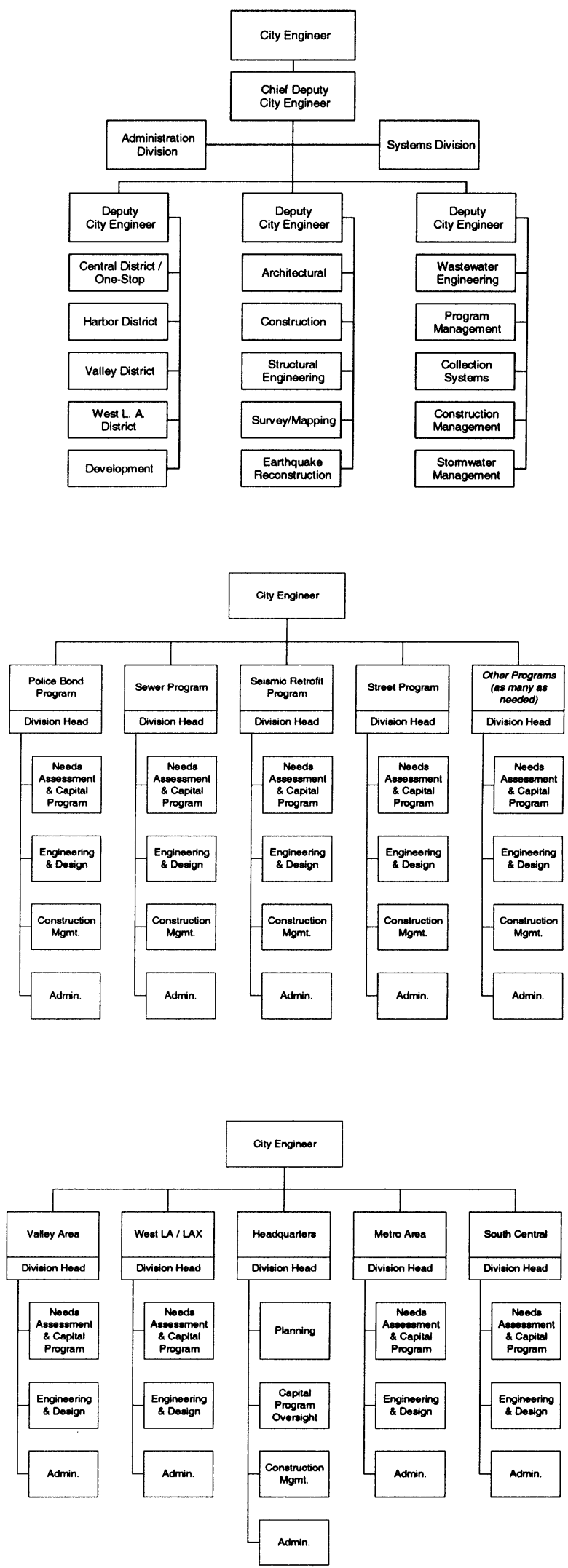

Fig. 1. Organizational options considered. 
Balanced Matrix: in a balanced matrix, the functional manager and the project manager share responsibility for the project resources. Under this form of matrix, project managers are assigned to oversee the project and interact on an equal basis with functional managers. Functional managers and project managers jointly direct project work and approve technical and operational decisions [1].

Project Matrix: in a project matrix, the functional managers authority is the smallest, with functional managers only assign resources for the project and provide technical consultation on an as-needed basis. Project managers are assigned to oversee the project and are responsible for the completion of the project [1].

In the analysis of the matrix organizational options, the Bureau opted for a hybrid functional matrix where the project and functional manager authorities are defined as for a classic functional matrix, but the matrix structures (between functional groups and project managers) are constructed around projects within programs with the program manager having complete authority over all projects in his or her program. Four main programs exist in the new matrix structure-Wastewater, Street, Stormwater, and Municipal Facilities. The new organizational structure of the Bureau is shown in Fig. 2 and was designated by the Bureau to be called a program based matrix.

\section{Implementation challenges}

Research has shown that successful implementation of a matrix structure in any form of organization can be expected to be difficult. The matrix implementation within the Bureau of Engineering did present several implementation difficulties specifically predicted in a review of the previous research literature. Table 1 shows a summary of implementation difficulties and how the Bureau implementation overcame the specific challenges predicted by past research on matrix organization implementation [4,5,13-17]. The first column in the table shows the implementation challenge identified through past research studies. The second column shows how these theoretical difficulties were in fact manifested in the implementation of the matrix organization at the Bureau of Engineering. Additional details on each of the challenges and solutions follows.

\subsection{Roles and responsibilities}

As expected based upon past research, confusion over roles and responsibilities is common within a matrix organization [13-15]. In turn, the Bureau experienced a significant amount of confusion and conflict over roles and responsibilities between functional managers leading design teams and project managers overseeing project performance. This was manifested through angry

Table 1

Implementation challenges and case study solutions necessity

Implementation challenge identified through past research (1)

Confusion and conflict over roles and responsibilities between functional managers leading design teams and project

managers overseeing project performance [13-15]

Need for a reporting system to monitor functional manager commitments [13]

Functional manager politicization of assignment of scarce resources between projects leading to project delays/changes and to changes in project prioritization $[13,16]$

The dual authority of a matrix requires people who are adaptive and comfortable with ambiguity to prevent negative influences to motivation and job satisfaction $[4,16]$ numerous interfaces inherent in a matrix structure require strong communication skills and an ability to work in teams $[4,17]$

A development program specific to project managers is needed to establish a common language and understanding of management processes [15]

Functional side of the organization becomes more powerful that the project side; functional managers do not gain a project focus [5]
Bureau of Engineering case study implementation solution (2)

Creation of summary lists of roles and responsibilities for functional and project managers

Creation of project design cost templatesfor all types of projects done within the Bureau and implementation of new project reporting and control system

Development and use of project prioritization protocol (policy approved by the City Engineer which became a standard Bureau practice)

All Bureau staff were trained in human relations training specifically pertaining to change, communication, and working in teams

Weekly mentoring sessions were held for all project delivery team members (functional or project). Monthly project manager roundtables were held with the project managers to share problems and solutions

Formalization of an annual project planning process that evaluates functional group performance based upon project based goals (number of projects completed and labor hours required to complete the projects) 


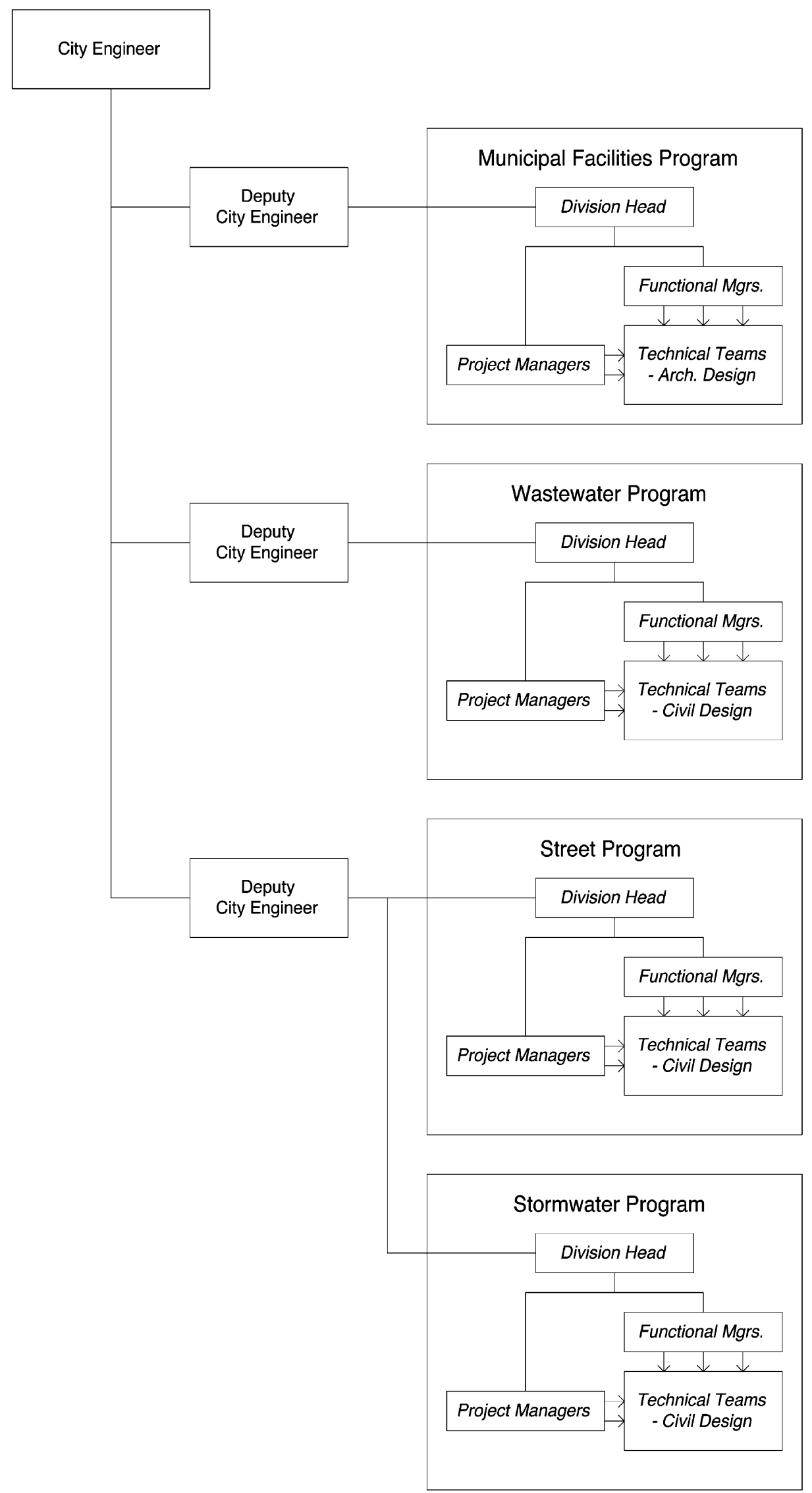

Fig. 2. Program based matrix structure. 
memos to supervisors, non-attendance at project meetings by functional managers, slowed delivery of design status reports to project managers, and lack of completion of certain administrative tasks with subsequent finger-pointing.

The solution to the problem was creation of written roles and responsibilities for both project and functional managers. A first attempt to create a comprehensive list of all tasks for both types of managers resulted in perhaps more confusion than assistance, as hundreds of tasks were identified and literally thousands of more specific duties could certainly have been identified for either position. A simpler and much more effective solution to the confusion and conflict was the compilation of a list of ten fundamental tasks for each position. These lists are shown in Fig. 3. All parties understood that these lists were by no means all-inclusive; rather they provided a foundation for each party's responsibilities. After the publication of these simple lists and 1 month of learning, the manifestations of confusion over roles and responsibilities reduced to practically zero with the managers having taught themselves who was to perform what specific tasks, often times with much compromise depending upon individual workloads.

\subsection{Reporting system}

A second implementation difficulty identified thorough past research literature and manifested within this case study was the need for a reporting system to monitor functional manager commitments [13]. Project manager monitoring and control of functional team design progress was practically non-existent since no written estimates of design task cost and schedule were available. Hence, the project managers had no control other than the functional manager's assurance that everything was fine. Reporting project performance is now accomplished by a new Project Management Control System (PMCS) created to monitor and control all projects within the Bureau. The PMCS tracks progress of all functional manager design teams. This tracking uses traditional measures of earned value and is reported at the project manager, and functional manager, and program manager levels.

Most important to this tool and to its success within the matrix organization is that the project manager ensures from the outset of any project that expectations, roles and responsibilities are established through formalized specific project agreements (called Handshake Agreements) in which all functional managers commit to project scope, budgets, and schedules for the various components of project delivery. Functional team duties vary based on the team, and they range from detailed civil engineering design to compiling environmental impact documentation to review of bidder compliance with respect to equal opportunity outreach to minority and woman owned businesses. When completed, these various Handshake Agreements become the commitments of the functional managers. Handshake Agreements for all Bureau project design processes on all projects were finalized by 1 June 1998. Most agreements were simple memorandum documents copied to all members of the project team and the project team supervisors.

Although simple in form, the Handshake Agreement commitments from the functional managers are based upon templates of historical functional team process performance. Unreasonable expectations cannot be imposed upon the functional managers by the project managers since all handshake agreement baseline values are negotiated from 21 pre-established project design templates which give specific dollar value and time duration values for every Bureau design sub-element based upon size and type of project. These templates eliminate the temptation for Project managers to "low ball" the design team to agree to an unrealistic performance standard, and prevent the temptation of the functional managers to over-inflate their estimates in order to appear productive. The Handshake Agreements can also be used to help eliminate bottlenecks created by poor resource leveling. Future agreements will include a master project schedule so that the functional managers know at what time each project is committed to be delivered and what functional team(s) will conduct the work. Hence, the functional managers will be less likely to over-commit his/her staff.

\subsection{Politicization of projects and resources}

The review of past research on matrix structures indicated that functional manager politicization of assignment of scarce resources between projects can lead to project delays and changes in project prioritization $[13,16]$. This was true within this study. In the past, even before the establishment of the matrix, many Bureau employees would make arbitrary changes to project prioritization based upon from which client they last received a phone call or to increase their stature in the eyes of city politicians. Upon the shift to a matrix structure, the Bureau created, published and began use of a formal project prioritization process under the signature of the City Engineer. The process is shown in Fig. 4. The process assigns each project within the Bureau a specific rank. Without Program Manager approval (in essence re-prioritization), no work is to be done on a lower rank project until the higher rank project is complete. Project templates Handshake Agreements are still used to establish functional team performance measures, but politicization of the team effort by the functional manager is eliminated by the new prioritization protocol. 


\section{PROJECT MANAGER ROLES AND RESPONSIBILITIES}

1. Responsible for project scope, budget and schedule throughout life of project. Will initiate dialogue with concerned stakeholders and, in conjunction with the clients and functional managers, will define/ revise project scope, budget and schedule as required.

2. Update the Program Management and Control System (PMCS) reports with the assistance of the project control engineer.

\section{Primary client and stakeholder contact.}

4. Develop, maintain and monitor Memorandum Of Understanding (MOU) for projects. Obtain required approvals/ signoffs for MOU. Generate timely Bureau of Engineering billings and monitor receipt of payments.

5. Responsible to see that project work orders are opened and closed.

6. Obtain administrative project design approvals, i.e. for client. Monitor progress of technical design approvals/signoffs.

7. Maintain project communication with project stakeholders per the Bureau of Engineering' Communication Protocol. Generate Board reports and obtain approvals for same.

४. MIonıtor cooraınatıon ana progress ot project through design, bid and award, construction and closeout phases.

\section{Administer consultant contract agreements.}

10. Participate in regular project information meetings with the program manager, functional managers, and project control engineer.

\section{FUNCTIONAL MANAGER ROLES AND RESPONSIBILITIES}

1. Complete assigned technical task(s)

2. Maintain technical task(s) scope, budget and schedule. Negotiates technical task scope, budget and schedule.

3. Provide data to project manager for PMCS updates.

4. Assist project manager in client discussions regarding MOU development and regarding technical elements.

5. Obtain required technical design approvals/signoffs.

6. Provide coordination/communication among his/her technical staff, other discipline's technical staff and consultants.

7. Provide coordination/communication between technical staff and Bid And Award unit.

8. Participate in regular project information meetings with program manager and project manager.

9. Supervise his/her technical staff.

10. Conduct design presentations to City Commissions, client and community. 


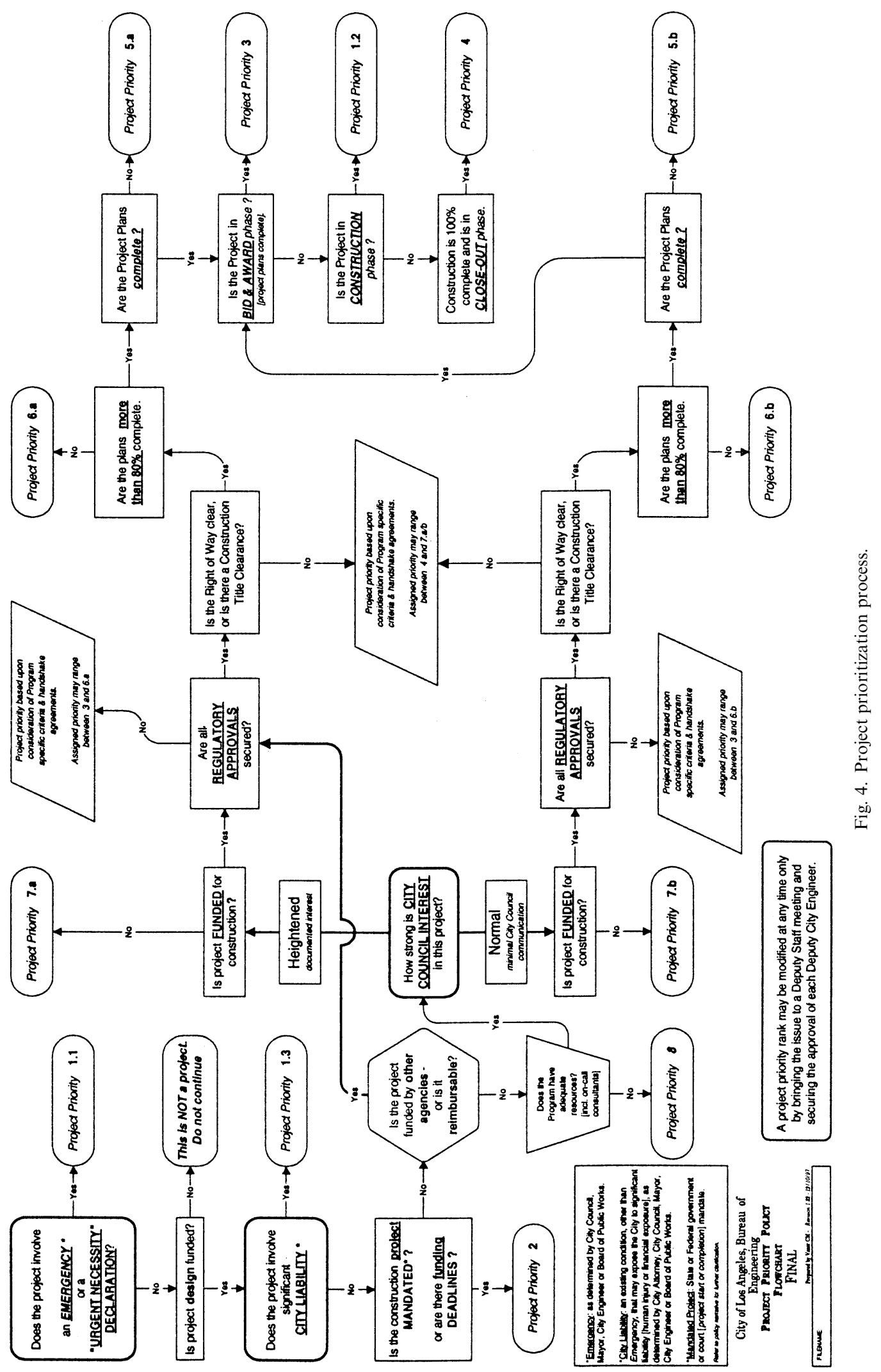


With the use of this new prioritization protocol, new projects can still be added to a program. When a new or "rush" project now enters a Bureau program, the importance of the project is assessed by the program manager using the flowchart to determine whether any ongoing design work should be stopped. If the ongoing work is stopped or resources reallocated, then clear documentation exists for the switch in the functional manager resource's effort and the change is at the discretion of senior executive level staff rather than the functional manager.

\subsection{Need skills training}

The numerous interfaces inherent in a matrix structure require strong communication skills and an ability to work in teams, while the dual authority of a matrix requires people who are adaptive and comfortable with ambiguity in order to prevent negative influences to motivation and job satisfaction $[4,16,17]$. The Bureau obviously did not wish to experience decreased morale as a result of the organizational shift. Hence, as part of the implementation, all Bureau staff were immediately trained in human relations training specifically pertaining to coping with change, communication, and working in teams. This training focused on the personal and practical staff needs identified in the research literature in order for the organization to be successful in the new matrix structure. A summary of the human relations training program is shown in Fig. 5.

Training on adapting to change and helping others adapt to change explored how disorientation, a normal reaction to change, can affect individuals and teams. The success of the Bureau during the restructuring depended on how people react and adapt. These modules focused on the crucial role leaders and managers play in effectively exploring change, introducing change, and helping others overcome resistance typically associated with change. Staff learned skills for conducting effective change discussions that minimized the potentially negative effects of change on morale, processes, and productivity.

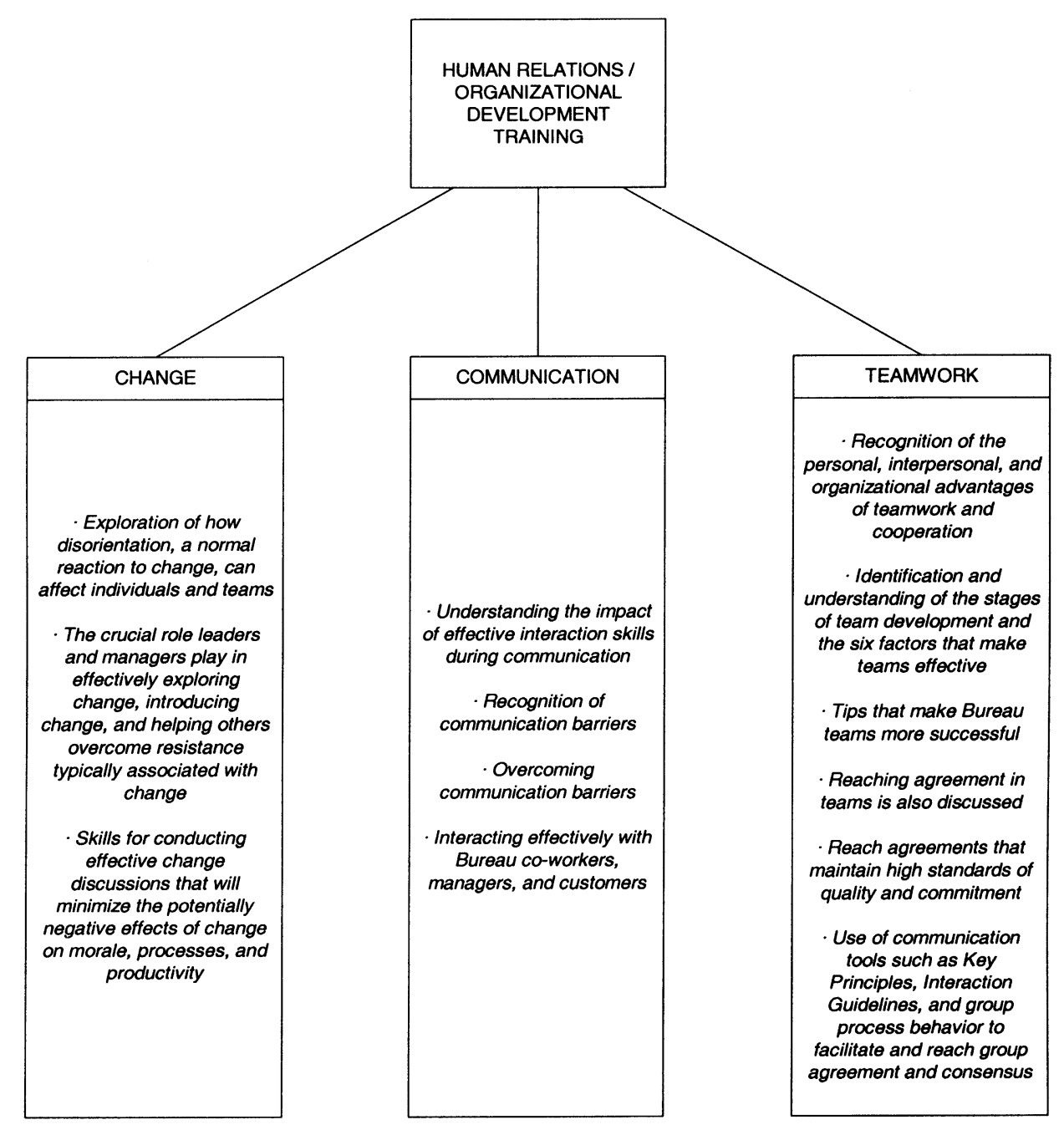

Fig. 5. Summary if human relation training. 
The communication training modules were designed to help participants understand the impact of effective interaction skills during communication. Bureau staff learned to recognize and overcome communication barriers and interact effectively with Bureau co-workers, managers, and customers. The working in teams' modules taught Bureau staff to recognize the personal, interpersonal, and organizational advantages of teamwork and cooperation - all skills identified to be critical to success within a matrix. Participants learned to identify and understand the stages of team development and the six factors that make teams effective. This training module also offered tips to make Bureau teams more successful, identified key team member skills, and introduced an action plan for participants.

\subsection{Continued project manager development}

Research literature indicates that for a matrix structure to thrive, a development program specific to project managers is needed to establish a common language and understanding of management processes [15]. In the case study of this implementation, this certainly was true. One urgent problem in the implementation was uncertainty (beyond the list of roles and responsibilities) over the position of project manager since the new position had no history and little recognition. The solution used was the Bureau was as prescribed by the research literature-provide mentoring. Mentoring supplied a forum for the new project mangers to receive direction and encouragement in performing their new tasks as well as educate key staff within the Bureau at to the duties of the new position. Weekly mentoring sessions were initiated for the new project mangers and selected functional managers. The focus of these sessions was on Department and City processes and how the project manager should participate in these processes. Topics discussed in these training sessions have included:

1. Federal funding projects.

2. Environmental documents and requirements.

3. The bid process - City requirements.

4. The award process - City requirements.

5. Supplier/Designer Handshake Agreements.

6. Funding of projects through the City Administrative Officer (CAO).

7. Resolution Authority process (funding of staff positions).

8. Role of the City's Contract administration inspector.

In addition this mentoring, when the matrix was first created, project managers held monthly roundtables. These roundtables were hosted by the Bureau programs and were meant to facilitate information exchange on the role of the project manager and how the manager works with other Bureau staff on day-to-day routine problems. Both the mentoring and roundtable were well received and are planned to be continued. Information presented at these sessions is also incorporated into a new, and continually expanding, project manager procedures guideline.

\subsection{Lack of project level focus}

Another potential difficulty of matrix implementation is that the functional side of the organization becomes more powerful that the project side. Hence, functional managers do not gain a project focus [5]. Given that the Bureau was implementing a hybrid function matrix, this predicted difficulty was manifested. When the matrix structure was first established, many functional managers took the view that as long as they still had supervisory control of their staff, no real change had taken place. They felt that the organization remained a traditional functional organization. This problem was recognized and was corrected by formalization of an annual project planning process.

Functional manager recognition of the importance of project delivery is now maintained through this new process - a yearly work program plan called the Work Program Resource Report (WPRR). This plan includes all projects that each functional team within a particular program are expected to complete. Based upon the predefined project design templates that provide a labor hour estimate for each project, functional team staff allocations for each year are made and checked versus project design performance. In the years since establishment of the matrix, by evaluating functional group performance based upon project based goals (number of projects completed and labor hours required to complete the projects), the Bureau has seen a dramatic increase in WPRR performance (as reported later).

\section{Performance under the matrix}

Performance improvements experienced by the Bureau as a result of functioning under the matrix structure are difficult to assess since performance can be measured at several levels. Studies and reports of a private sector engineering firm reorganized into a matrix structures found increased communication and flexibility while maintaining organizational accountability [18], more efficiency in multiple project deign work, as well as entrepreneurial stability for the firm [19], and reduced unbillable time and improved marketing [20]. As a public sector organization, performance measures are hard to define. Nonetheless, the Bureau has devised some measures and project delivery has improved. To date, the Bureau has measured performance across two levels: 
Table 2

Performance assessment under the matrix structure

Level of performance measurement (1)

Project Level

Program Level
Performance assessment under the matrix structure

(2)

For a $t$-test (two-sample assuming unequal variances with hypothesized mean difference $=0$ and alpha $=0.05$ ) the null hypothesis was proven true; therefore, the Bureau found no statistical difference in design costs between project completed in a matrix structure or under the old functional structure (sample size 243 projects) Street Program

$50 \%$ Improvement in annual capital program delivery in the Street Program (delivered 39 out of 41 projects with a budget of $\$ 60$ million)

$50 \%$ Improvement in annual capital program delivery in the Stormwater Program (delivered 25 out of 25 projects with a budget of $\$ 6$ million, in addition to 10 urgent necessity/emergency projects with a budget of $\$ 1$ million)

Creation and use of a standardized Memorandum of Understanding (MOU) to establish performance requirements of project (i.e. manner and method of payment, scope, budget, schedule, funding etc.) within the Municipal Facilities Program

1. Project level performance-how has the individual project performance in terms of meeting design cost objectives changed since the implementation of the matrix?

2. Program level performance-how has the program performance in terms of meeting annual goals/ commitments changed since implementation of the matrix?

Table 2 shows the results of the implementation across these two levels. The table shows that while the cost of completing any particular project has not statistically changed (based upon two-sample $t$-test with alpha $=0.05$ ) with the new matrix structure, the program commitments made during the annual funding/ budget cycle are now being satisfied much more completely.

- Additional performance measures beyond these two measures are continually developed and tested by the Bureau. Tools currently under development include:

- Client (i.e. City Department) review of Bureau performance through written surveys or questionnaires.

- Benchmarking of Bureau performance (project and program) against similar municipal agencies.

- Statistical process control charting of Bureau functional unit design costs.

Additional tools will inevitably be developed as the use of the matrix structure continues within the Bureau

\section{Conclusions and future research}

Past research on matrix organizational structure implementation has identified several implementation difficulties. The implementation of the matrix structure within the case study organization of this work has shown the past research to be accurate, with the documented research difficulties in fact being manifested in the case study. To address the difficulties experienced in the case study organization, the organization leaders developed polices implemented tools, and conducted training within the organization. This study has found that despite these implementation problems, the performance of the organization while operating under a matrix structure has improved.

The benefit of this work to managers is the documentation of this implementation. Specific benefits include information relating to:

- how the need for a matrix structure was identified;

- steps in the creation of the matrix and the organizational options also considered;

- process problems associated with the implementation;

- tangible, tested solutions to process problems associated with the implementation; and

- evaluation tools to measure the effectiveness of the project management process within the matrix organization.

Future research should continue to document this case study for years to come. Research should monitor 
- whether if any additional implantation difficulties arise;

- how the new tools and process described in this work evolve and perform with time; and

- whether the performance enhancements documented in this work continue to be achieved by the organization.

Additional research should attempt to identify whether any of the processes used within this case study implementation were used, or could be used, in other implementations (matrix or otherwise), and how the effectiveness of the tools varied from implementation to implementation. Additional research should also be conducted with respect to matrix performance. This work has focused on implementation. Enhanced performance as a result of the implementation appears to be taking place, but additional performance measures (new/established and quantitative/qualitative) need to be monitored and reported through research publications for many years to come.

\section{References}

[1] Larson EW, Gobeli DH. Matrix management: contradictions and insights. California Management Review 1987;29(4):126-38.

[2] Knight, K, editors. Matrix management. Gower Press, Teakfield Limited, Aldershot, UK, 1977.

[3] Gobeli DH, Larson EW. Matrix management: more than and fad. Engineering Management International 1986;4:71-6.

[4] El-Najdawi MK, Liberatore MJ. Matrix management effectiveness: an update for research and engineering prganizations. Project Management Journal 1997;28(1):25-31.

[5] Lawler EE. Rethinking organization size. IEEE Engineering Management Review 1999;27(2):3-10.
[6] Norby, L. Bond acceleration program benchmark report. Report by the Office of the City Controller, City of Los Angeles, January 1995.

[7] Barrington-Wellesley, Group, Inc. Benchmarking study of the bureau of engineering capital improvement program. Report to the City Administrative Office of the City of Los Angeles, February 1996.

[8] Capital Partnerships, Inc. Alternative organization and staffing of DWP's engineering and other CIP functions. Report to the Los Angeles City Council Ad Hoc Committee to Restructure the Public Works Department, September 1996.

[9] McCollum JK, Sherman JD. The Matrix structure: bane or benefit to high tech organizations. Project Management Journal 1993;24(2):23-6.

[10] McCollum JK, Sherman JD. The effects of matrix size and number of project assignments on performance. IEEE Transactions on Engineering Management 1991;38(1):75-8.

[11] Laslo Z, Goldberg AI. Matrix atructures and performance: the search for optimal adjustment to organizational objectives. IEEE Transactions on Engineering Management 2001;48(2):144-56.

[12] Tatum CB. New matrix organization for construction manager. Issues in Engineering Journal of Professional Activities 1981; 107(4):255-67.

[13] Pitagorsky G. The project manager/functional manager partnership. Project Management Journal 1998;29(4):7-16.

[14] Kuehn RR, Khandekar RP, Scott CR. The effects of marginality ad reward on matrix conflict. Project Management Journal 1996; 27(3):17-26.

[15] Johns TG. On creating organizational support for the project management method. International Journal of Project Management 1999;17(1):47-53.

[16] Babcock DL. Managing engineering and technology. Englewood Cliffs, New Jersey: Prentice Hall, 1991 (ISBN 0-13-552233-1).

[17] Turner SG, Utley DR, Westbrook JD. Project managers and functional managers: case study of job satisfaction in a matrix organization. Project Management Journal 1998;29(3):11-19.

[18] Bates GD, Roenker G, Junker DJ. A new matrix organization for a design firm. Issues in Engineering Journal of Professional Activities 1981;107(4):237-46.

[19] Birrell GS. Multiproject multidesigner work by matrix format. Journal of Professional Issues in Engineering 1984;110(1):37-53.

[20] Cardinal RJ. Matrix management may meet your needs for the 80s. Issues in Engineering Journal of Professional Activities 1980; 106(1):27-39. 